See discussions, stats, and author profiles for this publication at: https://www.researchgate.net/publication/333509111

\title{
Supervisor Support and Affective Organizational Commitment: The Mediator Role of Work Engagement
}

Article in Western Journal of Nursing Research · May 2019

DOI: $10.1177 / 0193945919852426$

\section{CITATIONS}

2 authors:

Alejandro Orgambídez

University of Malaga

84 PUBLICATIONS 567 CITATIONS

SEE PROFILE
READS

281

Helena Almeida

Universidade do Algarve

41 PUBlications 162 Citations

SEE PROFILE

Some of the authors of this publication are also working on these related projects:

Project The main barriers of Portuguese entrepreneurship ecosystem: Interpretive Structural Modeling (ISM) approach View project

Project SQSL:iHOTELS View project 


\begin{abstract}
The aim of the study was to verify the mediator role of work engagement between supervisor social support and affective organizational commitment. A cross-sectional and correlational study using questionnaires was conducted. We obtained a convenience sample of 267 participants from 403 nurses from two public hospitals (66.25\% response rate). Participants were required to be registered nurses without a supervisor position and to have worked for at least one year in the same ward in a public hospital. The mediator role of work engagement was examined using path analysis and bootstrapping method (Bias-Corrected Confidence Intervals). Results showed that affective organizational commitment was positively and significantly predicted by supervisor support, vigor and absorption. Supervisor support had both a direct effect and an indirect effect, through vigor and absorption, on affective organizational commitment. Social support from supervisors allows an increase both in nurses' engagement and their desire to remain in the organization.

Keywords: organizational commitment, social support, work engagement, supervisor nursing, hospital nursing staff
\end{abstract}


The continuity of nursing professionals is one of the main concerns of health organizations' directors and administrators. The intention of continuity in the enterprise is strongly related to organizational commitment, especially of an affective type: thus the study of previous affective organizational commitment takes on great importance, especially to a backdrop of budget and staff cuts (i.e. in public health systems).

In these previous studies, supervisor social support has been shown to be an important indicator of the affective organizational commitment in nursing. In this sense, the relationship between supervisor social support and the affective organizational commitment can be explained using the JD-R model, which assumes the intermediary role of work engagement between supervisor social support (job resource) and the affective organizational commitment (organizational result). Few studies have analysed the relationships between these variables in the context of nursing, so the aim of this study is to check the mediator role of work engagement between supervisor social support and affective organizational commitment.

\section{Organizational Commitment and Work Engagement in Nursing Staff}

Organizational commitment refers to the existence of a desire, an obligation or a need to remain a member of an organization (Meyer, Allen, \& Smith, 1993). There are three elements or types of links - affective desire, moral obligation and economic need - all of which rely on three dimensions or types of organizational commitment (Meyer et al., 1993): affective commitment, normative commitment and continuous commitment.

Affective organizational commitment refers to the emotional bond that the nurse has with their organization; the degree to which the nurse identifies with the values and targets of the institution. Normative organizational commitment is the extent to which a nurse feels a moral obligation to the organization and, and a result of this ethical obligation, feels that they should continue working there. Continuous organizational commitment refers to the extent to 
which it would be costly for the nurse to leave the organization, associated with the personal sacrifice involved and the lack of available alternatives for the person. Of the three types, affective organizational commitment is the one which is most strongly linked to the intention to remain in the organization (Gutierrez, Candela, \& Carver, 2012; Liou, 2008; Ruiller \& Van Der Heijden, 2016). The emotional bond involves both an acute need to be close to the company, and close identification with it, which produce a strong feeling of belonging and, consequently, the desire to remain in the organization.

Affective organizational commitment is one of the most significant consequences of work engagement (Gupta, Agarwal, \& Khatri, 2016; Santos, Chambel, \& Castanheira, 2016). Work engagement is defined as 'a positive, fulfilling, work-related state of mind that is characterized by vigor, dedication, and absorption' (Schaufeli, Salanova, González-Romá, \& Bakker, 2002, p. 74). Vigor refers to having high levels of energy at work, even when faced with obstacles and difficulties. Dedication refers to professional involvement, inspiration and pride taken in a job well done. Absorption refers to a high level of concentration on work tasks (Schaufeli et al., 2002; Schaufeli, 2017).

Literature research has shown that work engagement is an important predictor of organizational affective commitment in nursing staff, with samples from different countries (Brunetto et al., 2013; Gupta et al., 2016; Santos et al., 2016). Nurses who are engaged feel that their work is important: they put great effort and energy into their roles and are focused on their tasks, experiencing positive emotions and feelings in their workplaces and, as a result, develop a strong emotional bond with the organization, that is to say a strong affective organizational commitment. Consequently, the following hypothesis is proposed:

Hypothesis 1: Work engagement is positively related to affective organizational commitment

\section{Social Support from Supervisor and Organizational Commitment}


Supervisor social support is one the most significant elements in the context of nursing (Bhatti, Mat, \& Juhari, 2018; Othman \& Mohd, 2013; Toyama \& Saija, 2017) and is closely related to affective organizational commitment (Chang, 2015; El Akremi, Colaianni, Portogjese, Galletta, \& Battistelli, 2014; Gutierrez et al., 2012; Ruiller \& Van Der Heijden, 2016; Salami, 2010). Supervisor social support is defined as 'the overall level of helpful social interaction available on the job from supervisor' (Karasek \& Theorell, 1990, p.59) and consists of two types of support: socio-emotional and instrumental. The former refers to the expression of good will and positive emotions, trusting relationships and the empathy shown by the supervisor within a positive social environment. The latter refers to the collaboration in work tasks between nurse and supervisor, and includes aspects such as the availability of the supervisor to deal with the nurses' professional problems or to provide useful information for the job.

A number of studies have shown that social support from supervisors is a significant predictor of affective organizational commitment in nursing (Chang, 2015; El Akremi et al., 2014; Gutierrez et al., 2012; Ruiller \& Van Der Heijden, 2016; Salami, 2010). From a social exchange perspective, if nurses feel that their supervisors are taking an interest in them both instrumentally and emotionally, they feel more grateful for the support and the attention they receive, more integrated into the medical team and they identify more closely with the organization, and tend to show a greater desire to remain there thanks to the positive emotional bond which has been created (Othman \& Mohd, 2013). Consequently, the following hypothesis is proposed:

Hypothesis 2: Supervisor social support is positively related to affective organizational commitment

The Mediator Role of Work Engagement between Supervisor Social Support and Affective Organizational Commitment 
The relationship between social support, work engagement and affective organizational commitment can be explained by referring to the theoretical Job Demands-Resources (JD-R) (Schaufeli, 2017) model. This model suggests that work engagement is the result or consequence of the presence of increased job resources. Job resources are those aspects of the job which are useful in achieving work goals (i.e. correct information increases productivity). Supervisor social support is considered a significant job resource which helps to achieve work goals. Increased job resources, through work engagement, create positive results such as job satisfaction or organizational commitment (García-Sierra, Fernández-Castro, \& Martínez-Zaragoza, 2015; Schaufeli, 2017). That is to say, the JD-R model totally mediates the relationship between job resources and positive results in the organization (Schaufeli, 2017).

A number of studies with samples from nursing have fully confirmed the mediator role of work engagement between supervisor social support and positive results such as job performance rated by the supervisor (Bhatti et al., 2018) and creativity (Toyama \& Saija, 2017)). For their part, Santos et al. (2016) confirmed that work engagement mediates the relationship between relational job characteristics, such as job resources, and affective organizational commitment in Portuguese nurses. As a consequence, it is probable that work engagement mediates supervisor social support and affective organizational commitment. The socio-emotional and instrumental support supplied by the supervisors leads to the nurses having more energy at work, feeling more involved in what they do and being more focused on their tasks, creating a greater affinity with and sense of belonging to the organization, and developing stronger affective organizational commitment.

Therefore, we propose the following hypothesis:

Hypothesis 3: Vigor, dedication and absorption will fully mediate the relationship between supervisor social support and affective organizational commitment. 


\section{Methods}

\section{Design and Sample}

A transversal design with convenience sampling was used in this study. There were three selection criteria for the convenience sampling: (a) to be a registered nurse; (b) to have at least one year's experience working in the same unit in a state hospital; and (c) not to hold a supervisory position. A total of 403 nurses in two Portuguese state hospitals of the Regional Health of the Algarve (Agrupamento Algarve - I) who fulfilled the previously mentioned selection criteria were polled, giving a final convenience sample of 267 participants $(66.25 \%$ response rate).

The G*Power 3.1.9.3 program (Faul, Erdfleder, Lang, \& Buchner, 2007) was used to calculate the minimum sample size for the data analysis. For an anticipated medium effect size $\left(\mathrm{f}^{2}\right)$ of $.10, \alpha$ of .05 , power of .95 and four predictors (social support from supervisor, vigor, dedication, and absorption), the recommended minimum sample size is 191 .

179 participants were women $(67.04 \%)$ and the average age of the nurses was 37.12 years old $(S D=9.19)$. Regarding marital status, 124 of the participants were unmarried $(46.44 \%)$ and 116 were married (43.45\%). 171 participants of the sample reported that they had openended contracts (contracts of indefinite duration). The average professional experience in public hospitals was around ten years $(M=9.67, S D=8.57)$.

\section{Measures}

Supervisor social support. To measure social support from supervisors we used the dimension of supervisor support included in the Job Content Questionnaire (Karasek \& Theorell, 1990) adapted to Portuguese language (Vilas-Boas \& Cerqueira, 2017). The four items of the dimension were answered using a Likert-type scale from 1 (totally disagree) to 4 (totally agree). High scores indicated high levels of social support from supervisor perceived by the participants. The reliability of the scale, measured through Cronbach's alpha 
coefficient, was .93 in this study.

Work engagement. The reduced questionnaire of the Portuguese version of the Utrech Work Engagement Scale (UWES) (Schaufeli et al., 2002) was used to assess work engagement. The scale is made up of 9 items grouped into three dimensions, namely: vigor (3 items), dedication (3 items), and absorption (3 items). The participants answered the nine items using a Likert-type scale ranging from 0 (never) to 6 (always/every day). Higher scores indicated high levels of work engagement. Cronbach's alpha reliability coefficients were .84 for vigor, .88 for dedication and .82 for absorption in the present study.

Affective organizational commitment. To assess affective organizational commitment, we used the Portuguese version (Nascimento, Lopes, \& Salgueiro, 2008) of the affective dimension of the Organizational Commitment Scale (Meyer et al., 1993). The six items of affective commitment were answered using a Likert-type scale ranging from 1 (totally disagree) to 7 (totally agree). Higher scores indicated high levels of affective commitment with the organization perceived by the participants. The reliability of the scale, measured through Cronbach's alpha coefficient, was .78 in this study.

\section{Procedure}

We obtained the approval of the study from the ethics committees of the hospitals (Ethical Approval No. 258 - Regional Health of the Algarve - Portugal). After permission was granted, the researchers visited the units of the two public hospitals and approached potential participants who met the previous inclusion criteria. The objective of the study was presented to the registered nurses in their daily team meetings, and the questionnaires were delivered to the nurses who offered to collaborate.

On the cover sheet of the questionnaire, participants were informed that collaboration was totally voluntary, that anonymity and the confidentiality of the information provided were guaranteed. The researchers contact details were also facilitated. The participants gave their 
written consent before filling out the questionnaire. After completing the questionnaires, each questionnaire was placed in an envelope without any identification and given to the researchers.

\section{Data Analysis}

The STATA statistical package (v13) was used for the analysis of the data. A significance level of .05 (two-tailed) was assumed.

We proceeded to verify the possible effect of the common method variance (CMV) (Podsakoff, MacKenzie, \& Podsakoff, 2012). CMV is defined as "the systematic error variance that is shared among variables which are measured with the same source or method" (Richardson, Simmering, \& Sturman, 2009, p. 764) i.e. using self-report questionnaires. CMV can overestimate or underestimate the estimates of the relations between two or more variables (Podsakoff et al., 2012).

The data collection in this study was carried out through self-report questionnaires, so CMV is a relevant issue that needs to be evaluated (Podsakoff et al., 2012). Harman's SingleFactor test was used to confirm the possible effect of CMV. To perform Harman's test, all items of supervisor social support, work engagement, and affective organizational commitment scales were subjected to exploratory factor analysis (EFA). The principal component analysis method was used in the EFA with varimax rotation, and the extraction of a single factor was forced. If the extracted factor accounts for over 50\%, CMV may be a pervasive issue (Podsakoff et al., 2012). The results of the EFA showed a factor that explained $39.87 \%$ of the variance. Therefore, this test suggested that CMV does not seem to bias the results in the study.

We calculated the descriptive statistics of the variables (mean, standard error, skewness, kurtosis), the relationships between them (Pearson $r$ coefficient) and the reliability of the scales (Cronbach's alpha). Confirmatory factor analyses (CFAs) were carried out for 
validating the measurement model of the constructs in the study.

The relationships between social support from supervisor, work engagement and affective organizational commitment were examined using the path analysis technique, with the maximum likelihood (ML) estimation method. The variables related in the model were "scores obtained in the test and, therefore, fallible measurement that contained errors" (Acock, 2013, p. 62).

We used the following indexes to evaluate the adjustment of the model and the CFAs: RMSEA (Root Mean Square Error of Approximation), AIC (Akaike Information Index), CFI (Comparative Fit Index), TLI (Tucker-Lewis Index), and SRMR (Standardized Root Mean Square Residual). CFI and TLI values close to .95, and RMSEA and SRMR values less than .08 indicate a good fit. Also, the model with the lowest AIC value is the best fitting model (Schermelleh-Engel, Moosbrugger, \& Müller, 2003).

Mediation analysis was carried out using the bootstrapping method. This method permits the making of inferences and confidence intervals (CIs) for the indirect effects and has more statistical power compared to other mediation analyses (i.e. Sobel test). As recommended by Hayes (2013), Bias-Corrected (BC) bootstrap confidence intervals (95\%), based on 10,000 samples, were calculated. The indirect effect is significant $(p<.05)$ when the obtained CI for the estimate does not include zero.

\section{Results}

\section{Measurement Model}

To validate the measurement model of the constructs of the study, two confirmatory factor analyses were conducted in order to compare two models: M1 and M2. In the first model (M1), all the items of the scales saturated one common factor. The fit of the model was poor: $X^{2}(152)=1155.44, p<.001, \mathrm{RMSEA}=.18[90 \% \mathrm{CI}: .17 \square .19], \mathrm{CFI}=.60, \mathrm{TLI}=.55$, $\mathrm{SRMR}=.13$, and $\mathrm{AIC}=11523.47$. The second model $(\mathrm{M} 2)$ was composed of five factors 
(supervisor support, vigor, dedication, absorption, and affective commitment) with their respective items. This model showed an adequate adjustment according to the recommendations of Schermelleh-Engel et al. $(2003): X^{2}(138)=244.08, p<.001$, RMSEA $=$ .06 [90\% CI: $.05 \square .08], \mathrm{CFI}=.95, \mathrm{TLI}=.96, \mathrm{SRMR}=.06$, and $\mathrm{AIC}=10640.11$. Therefore, the results of the CFAs supported the fact that the measured variables are different constructs.

\section{Descriptive Statistics and Correlations}

Descriptive statistics, correlations and Cronbach's alpha of the scales are presented in Table

1. The mean score of social support from supervisor was $2.96(S D=0.88)$, indicating a moderate level of support in the workplace. Of the three dimensions of work engagement, the highest mean score was $4.71(S D=1.18)$ for dedication, and the lowest was $4.51(S D=1.12)$ for absorption. In conclusion, the participants were not particularly committed to their organization $(M=3.97, S D=1.11)$. Independent-samples t-tests were conducted to compare the scores for nurses from the two hospitals. There were no significant differences in social support from supervisor $(t(264)=1.23, p=.23)$, vigor $(t(263)=1.62, p=.30)$, dedication $(t(264)=1.01, p=.18)$, absorption $(t(264)=1.05, p=.17)$ or affective commitment to the organization $(t(264)=1.45, p=.40)$.

As expected, a significant and positive correlation was observed between supervisor support and affective organizational commitment $(r=.42, p<.001)$. In addition, the three dimensions of work engagement were significantly $(p<.001)$ and positively related to affective commitment to the organization: $r=.43$ for vigor, $r=.45$ for dedication, and $r=.44$ for absorption.

\section{INSERT TABLE 1 ABOUT HERE}

\section{Mediation Analysis}

We developed a path model in which vigor, dedication and absorption served as mediator variables between supervisor social support and affective organizational commitment. As 
recommended by Acock (2013), the path analysis was carried out following two steps: (a) designing an over-identified model; and (b) redesigning the model from the significant coefficients found during the previous step.

The path analysis revealed a final model with zero degrees of freedom. Figure 1 represents the standardized coefficients and significance levels obtained in the final model, using ML method as a parameter estimation procedure. The values of the explained variance $\left(R^{2}\right)$ of work engagement and affective commitment are also shown.

Vigor and absorption were positively and significantly $(p<.001)$ predicted by supervisor support. The beta values were .38 for vigor and .39 for absorption, explaining a variance of $14 \%$ and $16 \%$, respectively. Affective organizational commitment was positively predicted by vigor $(\beta=.24, p<.001)$, absorption $(\beta=.22, p<.001)$ and supervisor support $(\beta=.27, p$ $<.001)$. As such, Hypothesis 1 was partially confirmed and Hypothesis 2 was confirmed. The total of the affective commitment variance explained by vigor, absorption and supervisor support was $34 \%$. On the other hand, dedication was not a significant predictor of affective commitment.

\section{INSERT FIGURE 1 ABOUT HERE}

Bootstrap results showed that social support had a direct and positive effect (0.30) on affective organizational commitment, and an indirect effect on affective organizational commitment through vigor and absorption. The indirect effect was positive $(0.20)$ and significant $(p<.05)$, since zero was not included in the calculated interval [BC 95\% CI: 0.12

$\square 0.30] .60 \%$ of the effect of supervisor support on affective commitment was direct $(0.30 / 0.50)$, whereas $40 \%$ was indirect $(0.20 / 0.50)$. Consequently, mediating Hypothesis 3 can only be partially confirmed.

INSERT TABLE 2 ABOUT HERE

\section{Discussion}


Taking the JD-R model as a theoretical framework, the aim of this study was to verify the mediator role of work engagement in the relationship between supervisor social support and organizational commitment from a sample of registered Portuguese nurses. On the relationship between work engagement and affective organizational commitment, the results partially confirm the first hypothesis: only vigor and absorption were shown to be reliable predictors. When nurses dedicate energy and effort to their work and feel engrossed by it, they do their clinical tasks with greater efficiency and experience pleasant emotions at work. These positive emotions facilitate the creation of a positive emotional bond with the organization, creating strong affective organizational commitment among the nurses. In this sense, the relationships observed between work engagement and affective organizational commitment are consistent with the results obtained in other research with nursing staff (Brunetto et al., 2013; Gupta et al., 2016; Santos et al., 2016), where the global measure of work engagement was shown to be an accurate predictor of affective commitment to the organization.

The second hypothesis suggested that supervisor social support was positively connected to affective organization commitment. The results showed that supervisor social support was a positive and significant predictor of affective commitment to the organization, in line with the results from research by Chang (2015), El Akremi et al. (2014), Gutierrez et al. (2012), Ruiller \& Van Der Heijden (2016) and Salami (2010). When the supervisors direct clinical work and take an interest in the wellbeing of staff at a lower level, the nurses feel more integrated into their teams and feel more gratitude for the support received.

Consequently, they develop an emotional bond of belonging to the organization and greater affective organizational commitment, along with a strong desire to remain in the organization (Martín-Arribas, 2007; Othman \& Mohd, 2013).

The results of the current study partly confirm the third hypothesis, by observing that 
vigor and absorption partially mediate the effect of supervisor social support and the nurses' affective organizational commitment: supervisor social support had both a direct and an indirect effect. Instrumental support (i.e. orientation and advice for carrying out tasks) and socio-emotional support (i.e. concern for wellbeing) provided by supervisors meant nurses having higher levels of energy at work, even when faced with problems and difficulties, and of concentration on clinical tasks.

In turn, high levels of vigor and absorption are associated with pleasant feelings on the job, developing a feeling of belonging and a positive emotional bond with the organization, that is to say, strong affective commitment with the organization. The absence of the effect of dedication could be due to the fact that this aspect of work engagement may be related largely to identification with the nursing profession (i.e. pride, involvement) and less to the relationship between supervisors and nurses. Furthermore, the direct effect of supervisor social support can be explained by the theory of social exchange (Othman \& Mohd, 2013). Nurses may feel valued and grateful for the support they have received and, reciprocally, want to continue as a part of the organization.

The results obtained partially prove the mediator role of work engagement suggested by the JD-R model (Schaufeli, 2017) and observed in research carried out by Santos et al. (2016), Toyama \& Saija (2017) and Bhatti et al. (2018). Nonetheless, our results coincide with those seen by Saks (2006), who found a partial mediation between supervisor social support, work engagement and organizational commitment, albeit in a sample of service personnel.

The results of this study should be interpreted taking the following points into account. First and foremost, the design of the study allows us to establish a covariance hypothesis (predictor, mediator and result variable) in accordance with the JD-R model, but does not allow us to refer to a cause-effect relationship. Secondly, it is not possible to completely 
guarantee the absence of the CMV effect in the relationships studied (Podsakoff et al., 2012). Last but not least, the transversal design through questionnaires is especially sensitive to certain bias in the answers, such as social desirability or tiredness (Song, Son, \& Oh, 2015).

In conclusion, both supervisors' support and engagement seem to be significant antecedents in affective organizational commitment in nursing. The results partly confirm the mediator role of work engagement: supervisor social support has both a direct and an indirect effect, through vigor and absorption, on affective organizational commitment.

Future studies should focus on analyzing the effect of different types of social support (instrumental vs. socio-emotional) on work engagement and affective organizational commitment. Similarly, given the dynamic and fluctuating nature of commitment to the organization, longitudinal studies would be necessary to evaluate the effect of supervisor social support over time. By the same token, research into samples of nursing from other countries or samples made up of supervisor-nurse dyads would allow a more detailed analysis of the relationships between social support, engagement and affective commitment.

Nursing supervisors are fundamental components in the creation of the social support necessary for the development of positive work environments, which foster nurses' engagement and their commitment to the organization. In this sense, training of skills in order to provide both instrumental (i.e. advice, orientation) and socio-emotional support (i.e. active listening, personalised attention) can have significant positive effects on medical teams in terms of motivation, added to the development of a strong emotional bond with the organization.

With supervisors' social support, nurses not only feel more engaged with work but are also willing to remain in the organization, assuring the necessary stability in the workforce to offer excellent quality of care and services.

\section{References}


Acock, A. C. (2013). Discovering Structural Equation Modeling Using Stata. Texas, US: StataCorp LP.

Bhatti, M. A., Mat, N., \& Juhari, A. S. (2018). Effects of job resources on nurses job performance (mediating role of work engagement). International Journal of Health Care Quality Assurance, 31(8), 1000-1013.

Brunetto, Y., Xerri, M., Shriberg, A., Farr-Wharton, R., Shacklock, K., Newman, S., \& Dienger, J. (2013). The impact of workplace relationships on engagement, well-being, commitment and turnover for nurses in Australia and the USA. Journal of Advanced Nursing, 69(12), 2786-2799. doi:10.1111/jan.12165

Chang, C.-S. (2015). Moderating Effects of Nurses' Organizational Support on the Relationship Between Job Satisfaction and Organizational Commitment. Western Journal of Nursing Research, 37(6), 724-745. doi:10.1177/0193945914530047

El Akremi, A., Colaianni, G., Portogjese, I., Galletta, M., \& Battistelli, A. (2014). How organizational support impacts affective commitment and turnover among Italian nurses: A multilevel mediation model. The International Journal of Human Resource Management, 25(9), 1185-1207. doi:10.1080/09585192.2013.826713

Faul, F., Erdfleder, E., Lang, A. G., \& Buchner, A. (2007). G*Power 3: A flexible statistical power analysis program for the social, behavioral, and biomedical sciences. Behavior Research Methods, 39, 175-191. doi:10.3758/BF03193146

García-Sierra, R., Fernández-Castro, J., \& Martínez-Zaragoza, F. (2015). Work engagement in nursing: An integrative review of the literature. Journal of Nursing Management, 24(2), E101-E111. doi:10.1111/jonm.12312

Gupta, V., Agarwal, U. A., \& Khatri, N. (2016). The relationships between perceived organizational support, affective commitment, psychological contract breach, 
organizational citizenhip behaviour and work engagement. Journal of Advanced Nursing, 72(11), 2806-2817.

Gutierrez, A., Candela, L. L., \& Carver, L. (2012). The structural relationships between organizational commitment, global job satisfaction, developmental experiences, work values, organizacional support, and person-organization fit among nursing faculty. Journal of Advanced Nursing, 68(7), 1601-1614. doi:10.1111/j.13652648.2012.05990.x

Hayes, A. F. (2013). Introduction to mediation, moderation, and conditional process analysis. A regression-based approach. London: The Guilford Press.

Karasek, R., \& Theorell, T. (1990). Healthy work. Stress, productivity, and the reconstruction of working life. New York: BasicBooks.

Liou, S. R. (2008). An analysis of the concept of organizational commitment. Nursing Forum, 43(3), 116-125. doi:10.1111/j.1744-6198.2008.00103.x

Martín-Arribas, M. C. (2007). Estrés relacionado con el trabajo (modelo de demanda-controlapoyo social) y alteraciones en la salud: Una revisión de la evidencia existente [Workrelated stress (demand-control-social support model) and health alterations: a review of the existing evidence]. Enfermería Intensiva, 18(4), 168-181.

Meyer, J. P., Allen, N. J., \& Smith, J. C. (1993). Commitment to Organizations and Occupations: Extension and Test of a Three-component Conceptualization. Journal of Applied Psychology, 78, 538-551.

Nascimento, J., Lopes, A., \& Salgueiro, M. F. (2008). Estudo sobre a validação do modelo de compromisso organizacional de Meyer e Allen para o contexto português. Comportamento Organizacional e Gestão, 14(1), 118-133.

Othman, N., \& Mohd, A. (2013). Social support and work engagement: A study of Malaysian nurses. Journal of Nursing Management, 21(8), 1083-1090. doi:10.1111/j.1365- 
2834.2012.01448.x

Podsakoff, P. M., MacKenzie, S., \& Podsakoff, N. P. (2012). Source of method bias in social science research and recommendations on how to control it. Annual Review of Psychology, 63, 539-569. doi:10.1146/annurev-psych-120710-100452

Richardson, H. A., Simmering, M. J., \& Sturman, M. C. (2009). A tale of three perspectives: Examining post hoc statistical techniques for detection and correction of common method variance. Organizational Research Methods, 12(4), 762-800. doi:10.1177/1094428109332834

Ruiller, C., \& Van Der Heijden, B. (2016). Socio-emotional support in French hospitals: Effects on French nurses' and nurse aides' affective commitment. Applied Nursing Research, 29, 229-236. doi:10.1016/j.apnr.2015.06.006

Saks, A. M. (2006). Antecedents and consequences of employee engagement. Journal of Managerial Psychology, 21(7), 600-619. doi:10.1108/02683940610690169

Salami, S. (2010). Mentoring and work attitudes among nurses: The moderator roles of gender and social support. Europe's Journal of Psychology, 6(1), 102-126. doi:10.5964/ejop.v6i1.174

Santos, A., Chambel, M. J., \& Castanheira, F. (2016). Relational job characteristics and nurses' affective organizational commitment: The mediating role of work engagement. Journal of Advanced Nursing, 72, 294-305. doi:10.1111/jan.12834

Schaufeli, W. B., Salanova, M., González-Romá, V., \& Bakker, A. B. (2002). The measurement of engagement and burnout: A two sample confirmatory factor analytic approach. Journal of Happiness Studies, 3(1), 71-91. doi:10.1023/A:1015630930326

Schaufeli, W. B. (2017). Applying the Job Demands-Resources model: A 'how to' guide to measuring and tackling work engagement and burnout. Organizational Dynamics, 46, 120-132. doi:10.1016/j.orgdyn.2017.04.008 
Schermelleh-Engel, K., Moosbrugger, H., \& Müller, H. (2003). Evaluating the fit of structural equation models: Tests of significance and descriptive goodness-of-fit measures. Methods of Psychological Research Online, 8(2), 23-74.

Song, Y., Son, Y.-J., \& Oh, D. (2015). Methodological Issues in Questionnaire Design. Journal of Korean Academy of Nursing, 45(3), 323-328. doi:10.4040/jkan.2015.45.3.323

Toyama, H., \& Saija, M. (2017). Associations of Trait Emotional Intelligence with Social Support, Work Engagement, and Creativity in Japanese Eldercare Nurses. Japanese Psychological Research, 59(1), 14-25. doi:10.1111/jpr.12139

Vilas-Boas, M., \& Cerqueira, A. (2017). Assessing stress at work: The Portugese version of the Job Content Questionnaire. Avaliação Psicológica, 16(1), 70-77. doi:10.15689/ap.2017.1601.08 
Table 1

Descriptive statistics and correlations of the variables $(\mathrm{N}=267)$

\begin{tabular}{lccccccc}
\hline Variables & $M$ & $S D$ & 1 & 2 & 3 & 4 & 5 \\
\hline 1. Social support from supervisor & 2.96 & 0.88 & - & & & \\
2. Vigor & 4.61 & 1.10 & .34 & - & & \\
3. Dedication & 4.70 & 1.18 & .44 & .76 & - & \\
4. Absorption & 4.50 & 1.21 & .38 & .55 & .70 & - & \\
5. Affective organizational commitment & 3.97 & 1.11 & .42 & .43 & .45 & .44 & - \\
& & & & & & & \\
\hline
\end{tabular}

Note. $N=267$. All coefficients are significant $(p<.001)$ 
Table 2

Direct, indirect and total effects of social support from supervisor, vigor and absorption on affective organizational commitment among hospital staff nurses $(\mathrm{N}=267)$

\begin{tabular}{|c|c|c|c|}
\hline & $\begin{array}{l}\text { Direct effect } \\
{[B C 95 \% C I]}\end{array}$ & $\begin{array}{l}\text { Indirect effect } \\
{[B C 95 \% C I]}\end{array}$ & $\begin{array}{l}\text { Total effect } \\
{[B C 95 \% C I]}\end{array}$ \\
\hline$\overline{\text { Vigor }}$ & & & \\
\hline $\begin{array}{l}\text { Supervisor support } \rightarrow \\
\text { Absorption }\end{array}$ & $0.36[0.22-0.53]$ & (no path) & $0.36[0.22-0.53]$ \\
\hline $\begin{array}{c}\text { Supervisor support } \rightarrow \\
\text { Affective commitment }\end{array}$ & $0.41[0.24-0.59]$ & (no path) & $0.41[0.24-0.59]$ \\
\hline Vigor $\rightarrow$ & $0.28[0.15-0.41]$ & (no path) & $0.28[0.15-0.41]$ \\
\hline Absorption $\rightarrow$ & $0.24[0.11-0.36]$ & (no path) & $0.24[0.11-0.36]$ \\
\hline Supervisor support $\rightarrow$ & $0.30[0.17-0.43]$ & $0.20[0.12-0.30]$ & $0.28[0.15-0.41]$ \\
\hline
\end{tabular}

Note. $N=267 . \mathrm{BC} 95 \% \mathrm{CI}$ : Bias-Corrected Interval (95\%). Bootstrapping based on 10,000 samples. 
Figure 1

$\underline{\text { Standardized estimates of the final model }}$

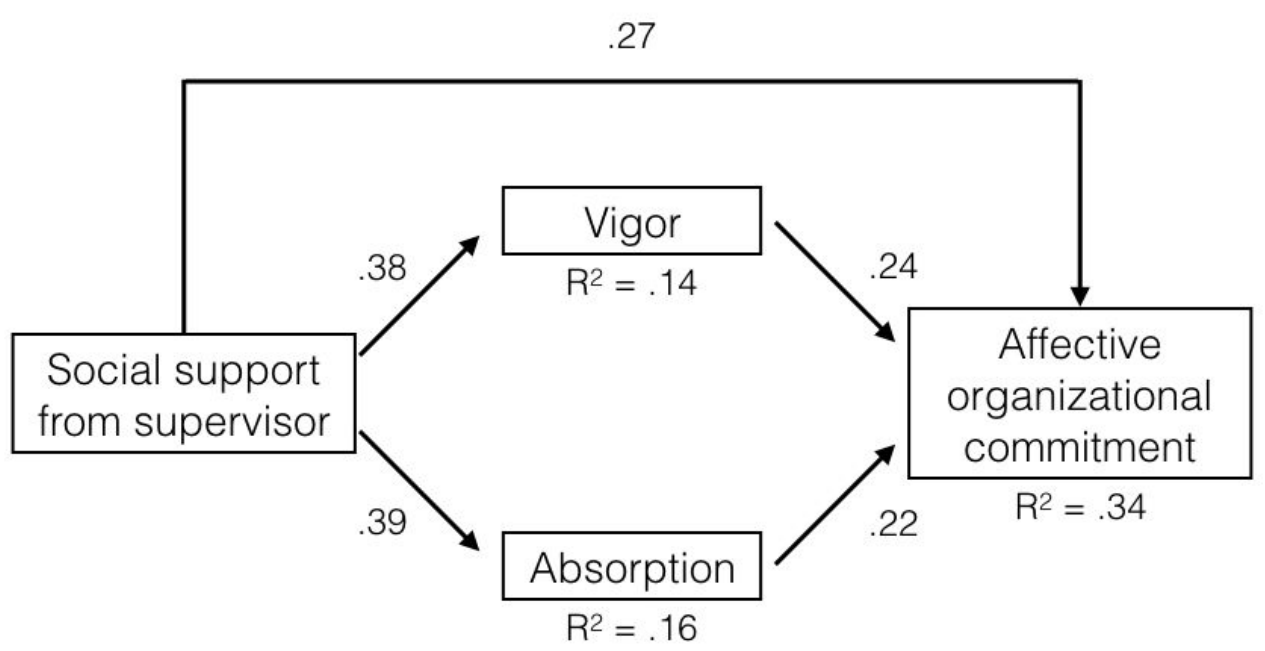

Note. $N=267$. All coefficients are significant $(p<.001)$ 